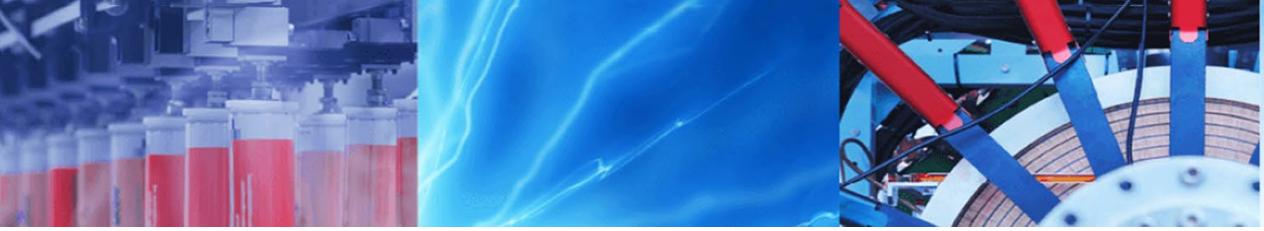

Research Article

\title{
Immunogenicity assessment of fungal L-asparaginases: an in silico approach
}

\author{
Lisandra Herrera Belén ${ }^{1,2}$. Jorge F. Beltrán Lissabet ${ }^{1} \cdot$ Carlota de Oliveira Rangel-Yagui $^{2} \cdot$ Gisele Monteiro $^{2}$. \\ Adalberto Pessoa ${ }^{2}$. Jorge G. Farías ${ }^{1}$ (i)
}

Received: 9 September 2019 / Accepted: 9 January 2020 / Published online: 16 January 2020

(c) Springer Nature Switzerland AG 2020

\begin{abstract}
Acute lymphoblastic leukemia is the most common cancer among children worldwide, characterized by an overproduction of undifferentiated lymphoblasts in the bone marrow. The enzyme L-asparaginase isolated from Escherichia coli and Dickeya chrysanthemi is a key factor in multiple therapies against this disease. Regardless of their effectiveness, these formulations present well-known adverse effects, highlighting the immunogenicity and allergenicity they cause. Some strategies have been adopted in this regard, such as PEGylation and modification by bioengineering as well as the search for new non-bacterial microorganisms producing the enzyme. Fungi have been shown to be asparaginase producers with high antitumor activity; however, little is known about the immunological features of fungal asparaginase. In this work, we developed the first immunoinformatics study focused on revealing the antigenic determinants that contribute to the immunogenicity of nine asparaginases of filamentous fungi experimentally tested, and compared them with the enzyme from E. coli. We were able to predict that the fungal asparaginases evaluated have a high degree of immunogenicity, which is an important result to consider if the aim is to produce clinical L-asparaginase from a fungal source. Likewise, for the first time, a bioinformatics-based approach was used to predict the immunogenic and allergenic epitopes present in fungal asparaginases.
\end{abstract}

Keywords L-asparaginase $\cdot$ Filamentous fungi $\cdot$ In silico $\cdot$ Immunogenicity $\cdot$ Epitope $\cdot$ Acute lymphoblastic leukemia

\section{Introduction}

L-asparaginase (ASNase) is considered a key therapeutic enzyme for the treatment of acute lymphoblastic leukemia (ALL) nowadays. This disease is recognized as the most frequent cancer among children [1], also affecting adults [2]. ALL consists of the overproduction of undifferentiated lymphocytes in the bone marrow, which can lead to death [3]. As part of the multiple therapy for the treatment of ALL, the enzyme ASNase has enabled remission rates over $90 \%$ to be reached [4]. Leukemic cells, unlike normal ones, are unable to synthesize asparagine in sufficient quantities, so they incorporate this amino acid from the circulation [5]. ASNase hydrolyzes the circulating amino acid, exerting its therapeutic action by starving the tumor cells [6]. There are currently four ASNase formulations available for clinical use from the bacterial source Escherichia coli [7-9] and Dickeya chrysanthemi [10]. Additionally, bacterial asparaginases present glutaminase activity, which has been reported

Electronic supplementary material The online version of this article (https://doi.org/10.1007/s42452-020-2021-z) contains supplementary material, which is available to authorized users.

Jorge G. Farías, jorge.farias@ufrontera.cl| 'Department of Chemical Engineering, Faculty of Engineering and Science, Universidad de La Frontera, Ave. Francisco Salazar 01145, P. O. Box 54-D, Temuco, Chile. ${ }^{2}$ Department of Biochemical and Pharmaceutical Technology, School of Pharmaceutical Sciences, University of Sao Paulo, Av. Prof. Lineu Prestes 580, Sao Paulo, Brazil. 
to be responsible of several side effects in patients [11-13]. Notwithstanding their pharmacological effectiveness, these formulations generate a wide range of adverse effects in patients [14-16]. However, the side effects best documented for this biopharmaceutical likely correspond to immunogenicity and allergenicity [17-19] due mainly to its prokaryotic nature [20]. The occurrence of hypersensitivity reactions has been related to the generation of antibodies, either IgG [21-24] or IgE type [25-27]. On the other hand, some reports have indicated that ASNase from E. coli is more allergenic than its equivalent from $D$. chrysanthemi $[28,29]$. The patient's immune response to ASNase not only results in undesirable effects at a clinical level, but also in decreased enzyme activity [30]. This is because the antibodies generated as part of the humoral response contribute to the inactivation of the enzyme, thus decreasing its half-life in circulation [31, 32].

One of the strategies adopted to reduce the immunogenicity caused by ASNase has been the search for new microorganisms capable of producing the enzyme with a lower risk of causing side effects in patients [33-35]. In this regard, fungal sources have been explored for their eukaryotic nature, as their similarity to humans at cellular level could reduce the unwanted immunological reactions [36, 37]. Several reports [38-41] and comprehensive reviews [20,42-44] have been published, revealing the potential of fungi as a feasible source of ASNase and presenting antitumor activity $[45,46]$. In addition to being eukaryotes, they can produce ASNase with reduced glutaminase activity $[47,48]$. In spite of a high antitumor activity having been demonstrated in vitro using fungal enzymes [49-51], the immunological implications in patients have been scarcely explored.

The use of bioinformatics tools for evaluating immunological responses from an in silico approach has been addressed in many studies in recent years [52-57]. Several have focused on explaining antigenic epitopes in the structure of various proteins, including ASNase, for subsequent modification and reduction of immunogenicity [58-61]. All this knowledge in the bioinformatics arena offers an opportunity to discover and develop new safer and more effective biopharmaceuticals.

In this work, we present the first in silico study that describes L-asparaginase from nine experimentally tested filamentous fungi species in terms of their predicted immunogenicity profile. Our objective is to show the structural features that could be responsible for generating an immunological reaction in patients, after the administration of fungal ASNase, also predicting for the first time the composition of the peptides that contribute to the allergenicity of fungal ASNase. These findings are of great significance in the development of therapeutic asparaginases from new sources.

\section{Materials and methods}

\subsection{L-asparaginase sequence dataset}

For this study, the amino acid sequences of nine fungal L-asparaginases were downloaded from the National Center for Biotechnology Information (NCBI) Protein Database (https://www.ncbi.nlm.nih.gov/protein) and the UniProtKB Database (https://www.uniprot.org/). Table 1 shows the filamentous fungi selected for the study, whose activity has previously been proven. Additionally, the amino acid sequence of Escherichia coli type II (EcA) L-asparaginase was downloaded from the Protein Data Bank (https:// www.rcsb.org/). All the sequences appear in Supplementary Material A.1.

\subsection{T-cell epitope prediction and epitope density determination}

For T-cell epitope prediction the NetMHCII 2.3 Server (http:// www.cbs.dtu.dk/services/NetMHCII/) was used [57], setting

Table 1 Filamentous fungi used for the in silico immunogenicity analysis of L-asparaginases in the current research

\begin{tabular}{ll}
\hline Filamentous fungi species & References \\
\hline Aspergillus niger & {$[62,63]$} \\
Aspergillus terreus & {$[37,48,64]$} \\
Aspergillus flavus & {$[43,65]$} \\
Fusarium oxysporum & {$[40,66,67]$} \\
Penicillium digitatum & {$[36]$} \\
Penicillium chrysogenum & {$[63,68]$} \\
Aspergillus tubingensis & {$[62]$} \\
Aspergillus nidulans & {$[66,69]$} \\
Beauveria bassiana & {$[70]$} \\
\hline
\end{tabular}

The different colored areas correspond to the predicted B-cell epitopes in each asparaginase 
the default parameters of the program. The peptides predicted as "strong binder" $(\leq 2 \%)$ and "weak binder" $(\leq 10 \%)$ were selected as immunogenic epitopes. For epitope density computation, the relative frequency was used: $f_{i}=n_{i} / N=n_{i} / \sum_{j} n_{j}$, where $n_{i}$ is the number of immunogenic epitopes predicted, and $N$ is the total number of epitopes determined by the program (immunogenic and non-immunogenic). The HLA-DRB1*01:01, HLA-DRB1*03:01, HLA-DRB1*04:01, HLA-DRB1*07:01, HLA-DRB1*08:01, HLA$D R B 1^{*} 11: 01, H L A-D R B 1 * 13: 01$ and HLA-DRB1*15:01 alleles were used for the prediction because these are reference alleles with a high distribution worldwide [71, 72].

\subsection{Prediction of epitope allergenicity}

In order to perform the allergenicity prediction of the nine fungal asparaginases, the AllerTOP v. 2.0 server (http:// www.ddg-pharmfac.net/AllerTOP/) was used [73]. For this purpose, each of the T-cell epitopes predicted as immunogenic for the $H L A-D R B 1^{*} 07: 01$ allele for the nine fungal and E.coli ASNase were evaluated using this program. The program evaluates the sequence of peptides and returns the results as "probable allergen" or "probable non-allergen."The relative frequency of the predicted allergenic epitopes was calculated, dividing the number of immunogenic epitopes for the HLA-DRB1 * 07: 01 allele over the total immunogenic epitopes previously determined as described for each ASNase in Sect. 2.2.

\subsection{Modeling, refinement and quality assessment of tertiary structures of fungal ASNase}

The sequences of the nine fungal ASNases were used for homology modeling of their tertiary structures, with the Phyre2 program [74]. Subsequently, the models were refined with the GalaxyRefine tool [75], and the quality of the generated models was assessed with the MolProbity tool [76], available in Swiss-Model.

\subsection{B-cell epitope prediction and mapping}

We performed the B-cell epitope prediction (linear epitopes) by using the ElliPro server (http://tools.iedb.org/ellipro/) [77] from the IEDB Analysis Resource database. For this analysis, we used the monomeric structures of the nine fungal
ASNase previously modeled. The epitope mapping in the modeled structures of fungal asparaginases was carried out with PyMOL (PyMOL Molecular Graphics System, Version 2.0 Schrödinger, LLC).

\subsection{Statistical analysis of the epitope density}

A comparative analysis of epitope density of the L-asparaginases was performed by using a one-way ANOVA with Tukey's test a posteriori. Probability values $(p \leq 0.05)$ were considered significant. The analysis was carried out with the GraphPad Prism package version 5.0 for Windows (GraphPad Software, San Diego, California, USA).

\section{Results and discussion}

The identification of immunogenic epitopes in the protein structure by computational tools has been a strategy used to achieve a reduction in the immunogenicity of several proteins [78-80]. It is also the case of ASNase from E. coli, where the use of bioinformatics techniques has allowed engineering the enzyme with the aim of obtaining an improved therapeutic agent [58, 81, 82]. On the other hand, the search for novel sources such as yeast and fungi has provided a new niche for obtaining less immunogenic ASNase [34, 83-85]. In our work, we address the problem of asparaginase immunogenicity through the evaluation of enzymes from nine filamentous fungi using computational tools. For this, we applied the measure known as relative frequency, since it has been used in previous studies to determine the immunogenic epitope density present in several proteins, correlating this measure with their immunogenicity level [86-91].

In assessing the degree of asparaginase immunogenicity, we found that there were no significant differences in the predicted immunogenicity between the nine fungal ASNases evaluated (Fig. 1). However, when comparing the relative frequencies of these asparaginases with that obtained for the enzyme from E. coli, interestingly, the predicted immunogenicity degree of fungal asparaginases was equivalent to the bacterial enzyme and even higher in the particular cases of Penicillium digitatum (Fig. 1). These results are remarkable: 
Fig. 1 Statistical analysis of the relative frequency of predicted immunogenic T-cell epitopes in fungal and bacterial asparaginases for eight alleles $(H L A-D R B 1 * 01: 01, H L A$ $D R B 1 * 03: 01, H L A-D R B 1 * 04: 01$, HLA-DRB1*07:01, HLA$D R B 1^{*} 08: 01, H L A-D R B 1^{*} 11: 01$ HLA-DRB $1^{*} 13: 01$ and HLA$\left.D R B 1^{*} 15: 01\right)$. Significant differences were observed only between Penicillium digitatum versus Escherichia coli $(p=0.05)$. Error bars represent the standard deviation of the data set

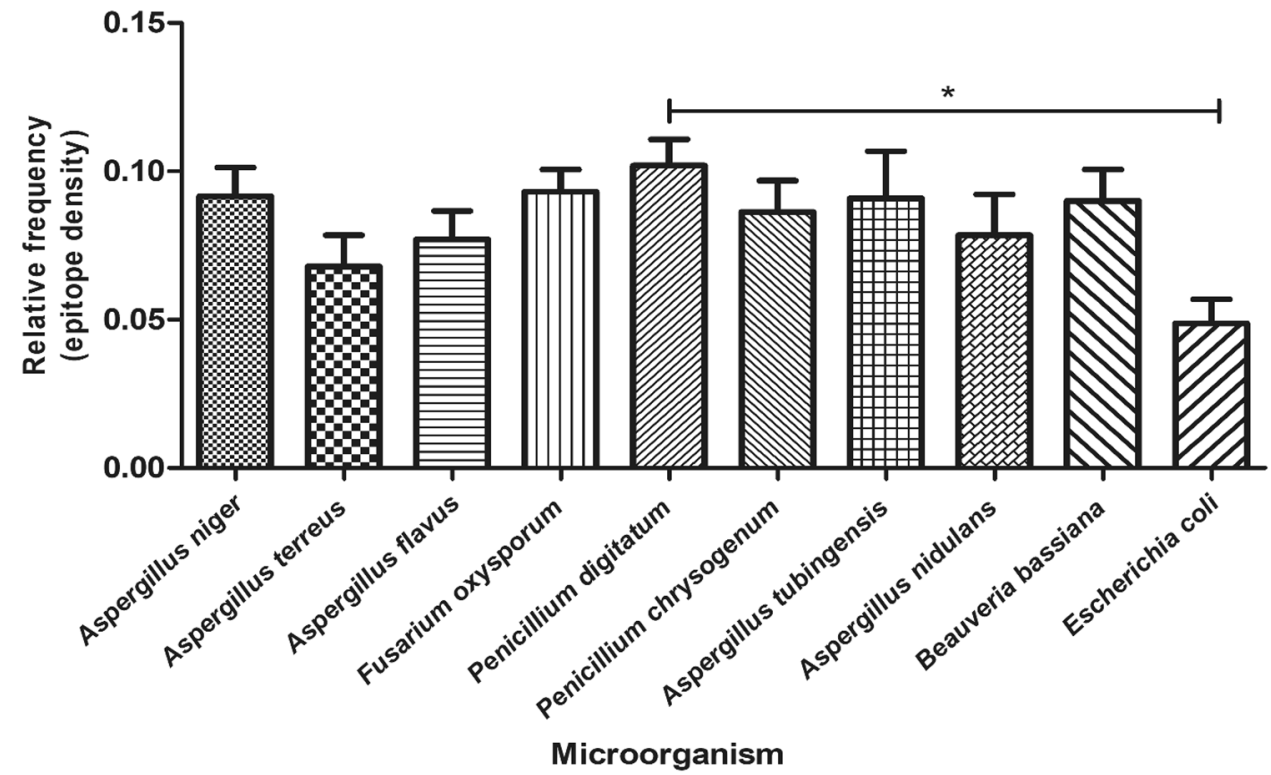

first, because they constitute the only report to date that refers to a study of the immunogenicity of fungal L-asparaginase, and second because they contradict expectations as to the possible safety of this enzyme derivative from eukaryotic cells. However, considering the analysis performed, an immune response analogous to that of the E.coli ASNase could be likely if the enzyme derived from one of these evaluated species were used. Therefore, although it is promising to obtain ASNase with an activity from the nine species of fungi reported, this activity will presumably be affected after recognition by the immune system, which could lead to subsequent neutralization, as in the case of bacterial ASNase. The predicted immunogenic T-cell epitopes are presented in Table B.1 as Supplementary Material.

Since HLA-DRB1 alleles confer high-affinity binding to ASNase epitopes causing several allergic reactions [92, 93], we compared the relative frequency of T-cell epitopes for the eight alleles evaluated. Significant differences were observed between the $H L A-D R B 1^{*} 01: 01$ allele versus the HLA-DRB 1*08:01, HLA-DRB1*11:01, HLA-DRB 1*13:01 and $H L A-D R B 1^{*} 15: 01$ alleles, respectively (Fig. 2 ). In previous research, the $H L A-D R B 1^{*} 01: 01$ allele has been linked to the occurrence of hypersensitivity reactions associated with the administration of the antiretroviral drugs nevirapine and efavirenz, used in the treatment of patients infected with HIV [94-96]. This allele was also associated with the occurrence of hypersensitivity reactions producing liver damage after administration of the nonsteroidal anti-inflammatory lumiracoxib [97]. However, this is the first report that highlights the association between the $H L A-D R B 1 * 01: 01$ allele and the probable occurrence of immunological reactions against asparaginases, particularly those obtained from fungal sources. In our study, significant differences were also observed between the HLA-DRB1*04:01 allele and the HLA-DRB1*11:01 and HLA$D R B 1 * 13: 01$ alleles, respectively (Fig. 2). HLA-DRB 1*04:01 allele has previously been associated with an immune system response in the case of the therapeutic protein interferon- $\beta$ [98].

By contrast, it has been well established that the HLA$D R B 1^{*} 07: 01$ allele is associated with a high risk of hypersensitivity reactions after treatment with bacterial ASNase, possibly due to it being a high-binding allele $[93,99]$. In our work, we performed a predictive analysis of the relative frequency of allergenic T-cell epitopes for the HLA$D R B 1 * 07: 01$ allele in the nine fungal asparaginases, comparing them with the enzyme from E. coli. Surprisingly, a high epitope density was observed for fungal asparaginases in comparison with the bacterial one, underscoring 
Fig. 2 Relative frequency of predicted allergenic T-cell epitopes for the eight alleles evaluated and the nine fungal asparaginases, by using the AllerTOP v. 2.0 server. Significant differences were observed between the $H L A-D R B 1^{*} 01: 01$ allele versus the $H L A-D R B 1 * 08: 01, H L A$ $D R B 1^{*} 11: 01, H L A-D R B 1^{*} 13: 01$ and $H L A-D R B 1^{*} 15: 01$ alleles. In addition, significant differences were observed between the $H L A-D R B 1^{*} 04: 01$ allele versus the $H L A-D R B 1^{*} 11: 01$ and $H L A$ $D R B 1 * 13: 01$ alleles $(p=0.0010)$. Error bars represent the standard deviation of the data set

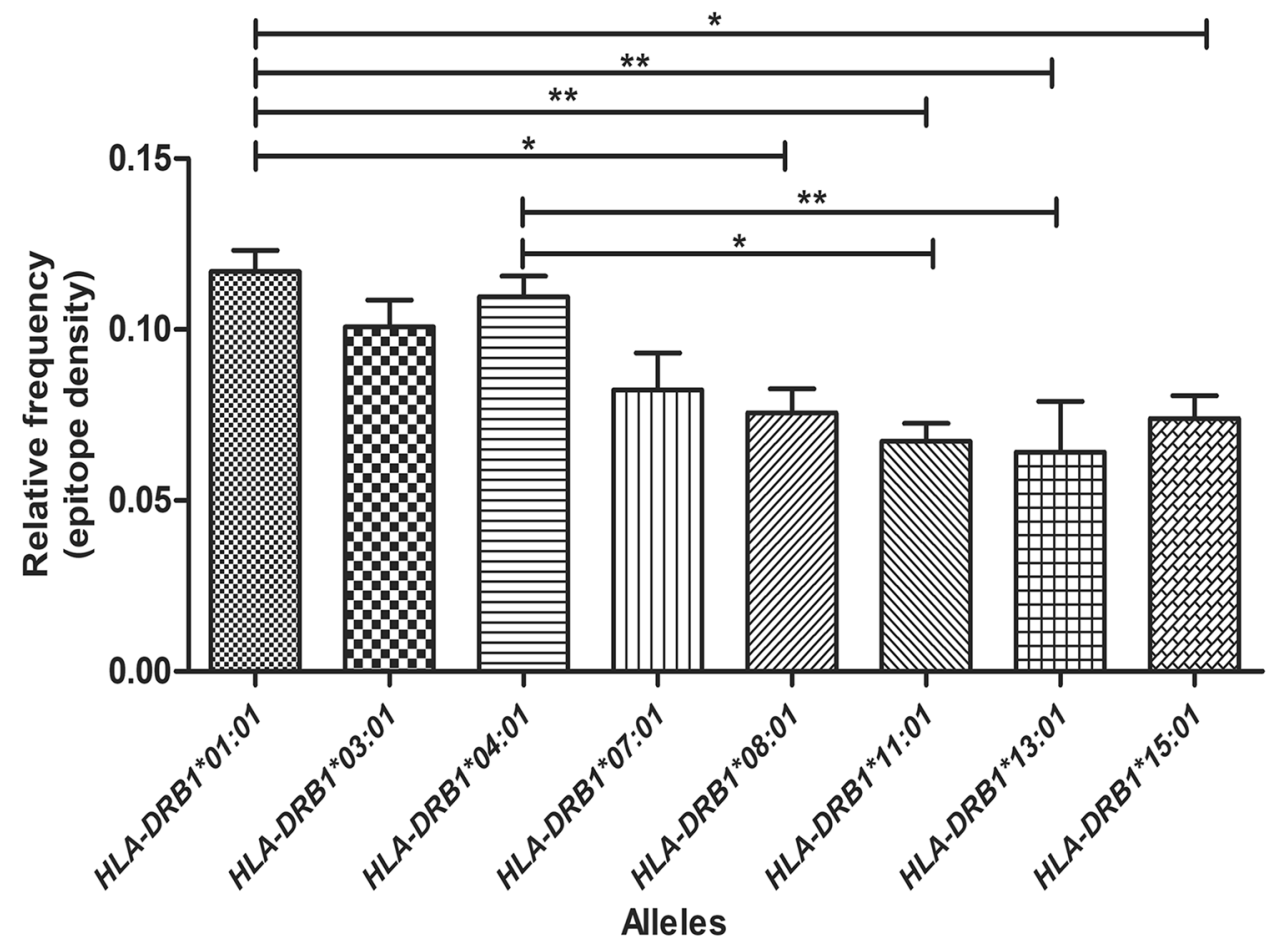

the highest values for the Penicillium chrysogenum and Aspergillus terreus species (Fig. 3). The predicted allergenic T-cell epitopes are summarized in Supplementary Table B.2. Hypersensitivity reactions caused by E. coli ASNase have been widely studied in vivo due to their high incidence [100-103]. However, fungal ASNase has not been explored in this regard.

HLA-DRB1*07:01

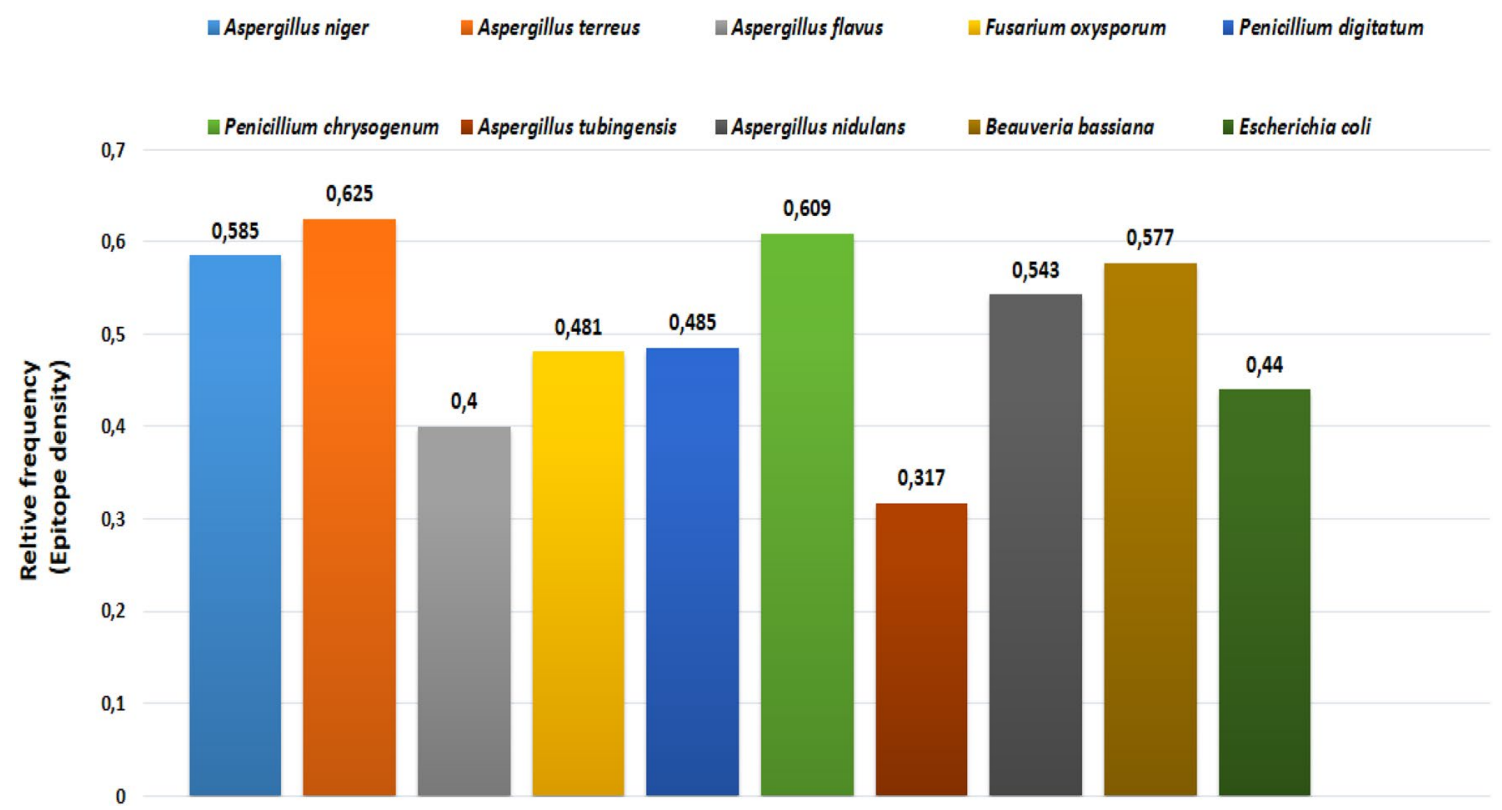

Fig. 3 Relative frequency of allergenic T-cell epitopes for the HLA-DRB1*07: 01 allele for the ten microorganisms studied. A high epitope density was observed for fungal asparaginases 
A. flavus
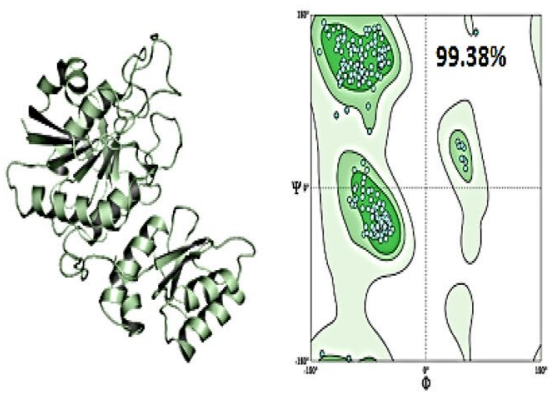

A. terreus

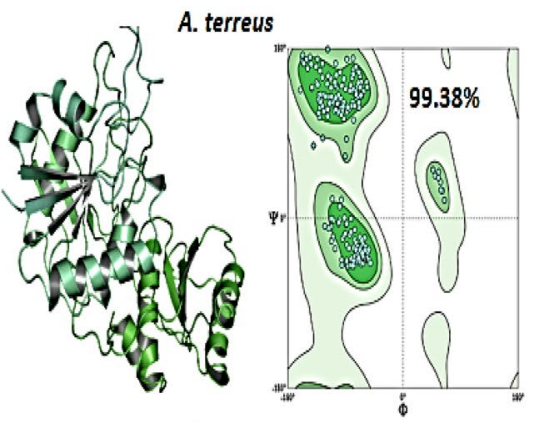

F. oxysporum

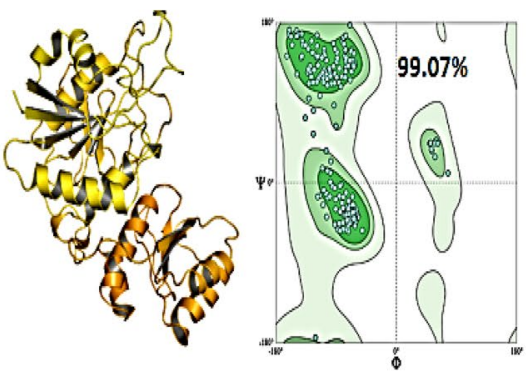

A. nidulans
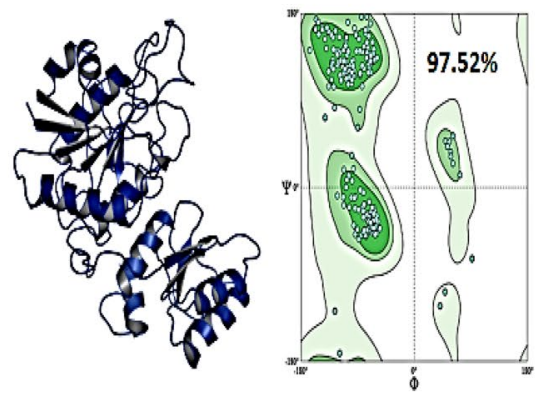

A. tubingensis

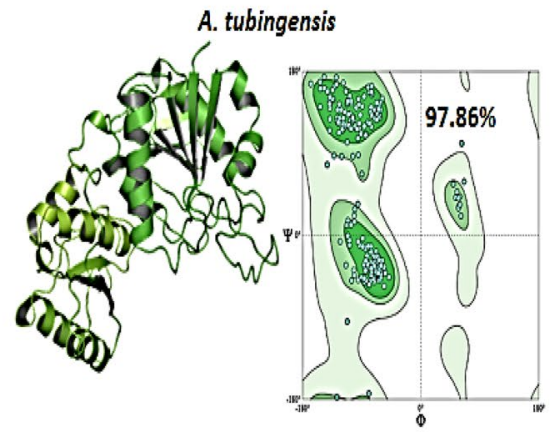

P. chrysogenum

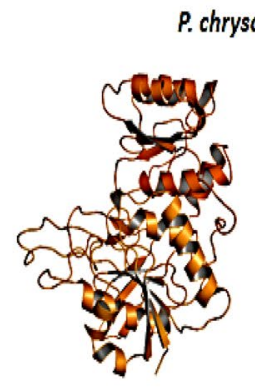

A. niger

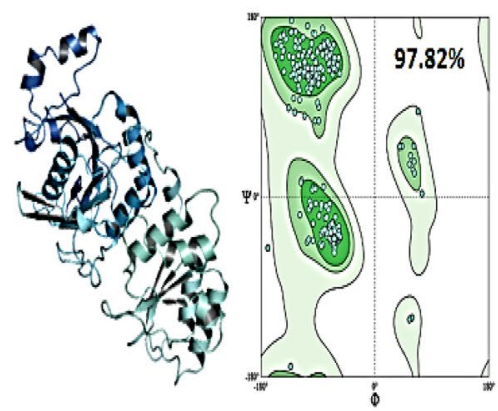

B. bassiana

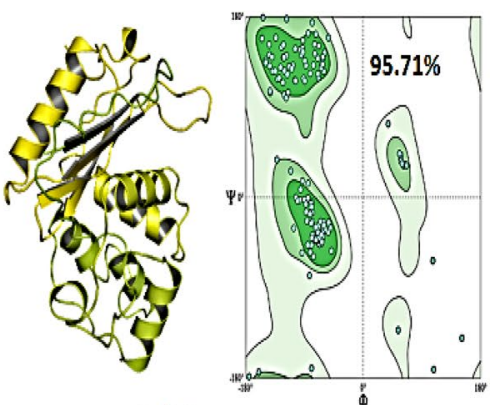

P. digitatum
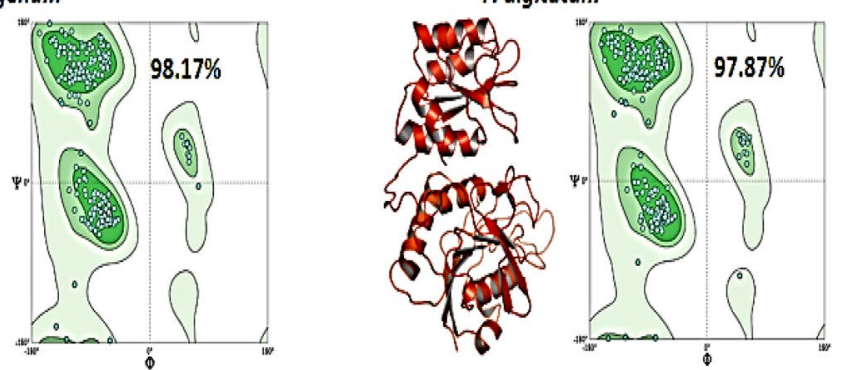

Fig. 4 Monomeric three-dimensional models predicted for the nine fungal ASNase and quality assessment using Ramachandran plots. All predicted models showed a quality higher than $95 \%$

B-cell epitope identification has been a widely used approach in peptide-based vaccine design and disease diagnosis [104-106]. Additionally, we identify the linear B-cell epitopes present in the nine fungal and E.coli ASNase. Previously, we modeled the monomeric threedimensional structure of fungal ASNase, since these are not crystallized or reported. We present the predicted models in Fig. 4, as well as the quality assessment of these models. As can be seen in the Ramachandran plot, all the models present more than $95 \%$ of their amino acid residues in favorable regions, suggesting that the predicted models have a high quality. Supplementary Material C.1 summarizes the linear B-cell epitopes identified in the monomeric structure of the nine fungal and $E$. coli ASNase, while Fig. 5 shows the mapping of the B-cell epitopes identified. In general, the results show that the immunogenic B-cell epitope distribution in fungal ASNase as well as their length (Supplementary Table C.1) is very similar to the pattern in E.coli. This finding reinforces the fact that the immune response generated by the fungal ASNase could be very similar to that generated by E.coli in patients, as suggested from the results obtained in the prediction of 

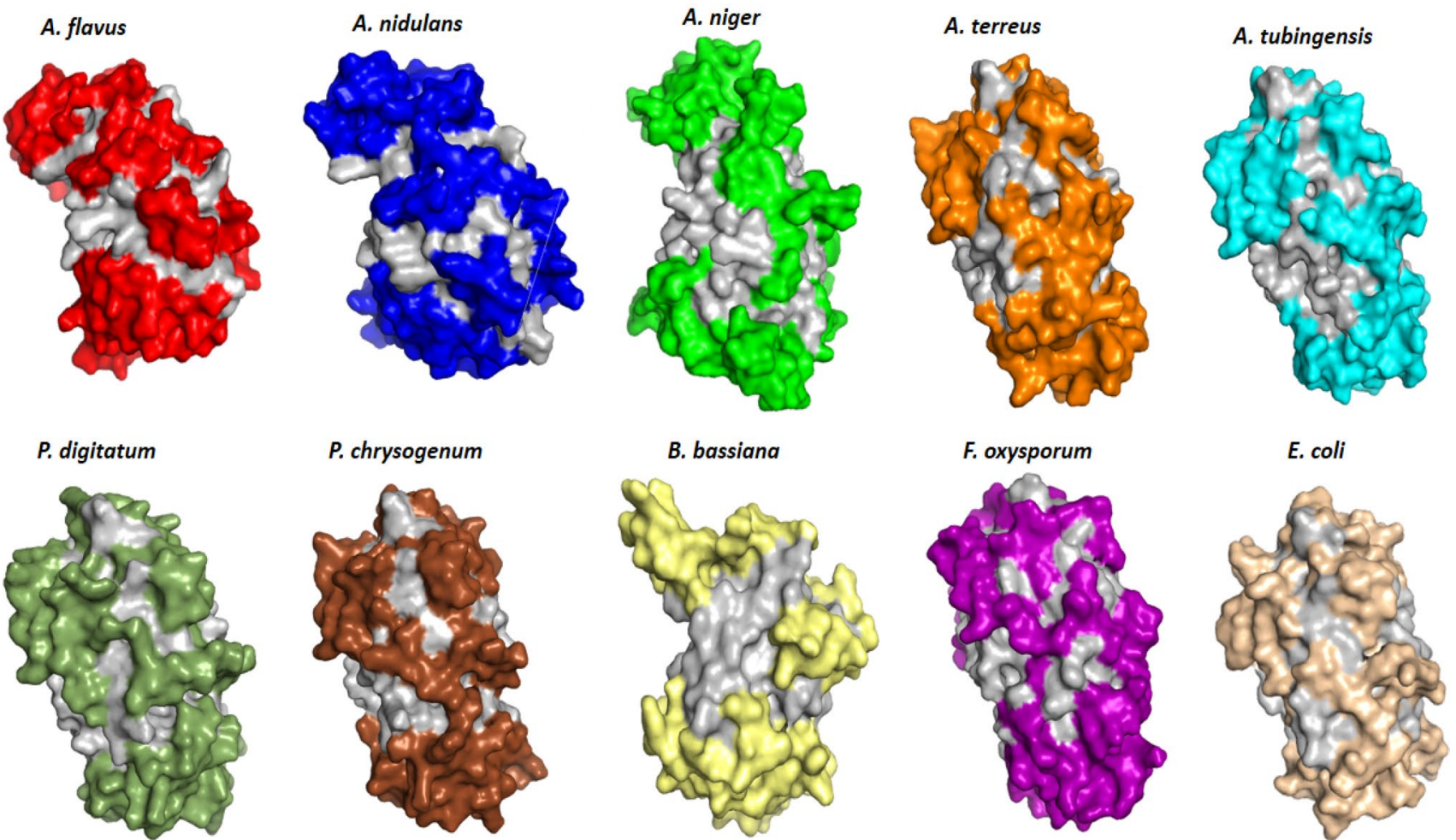

Fig. 5 Mapping of predicted B-cell epitopes in nine fungal asparaginases and E.coli

T-cell epitopes. All these reports offer new insights about the choice of fungal ASNase as a possible alternative for the treatment of ALL because, although they are attractive as producers of the enzyme, the way in which the immune system of patients could respond to their administration is detrimental to its quality at industrial level.

\section{Conclusions}

This research is the first study to determine the immunogenicity of fungal L-asparaginases using an in silico approach, also showing the allergenic peptides predicted in the nine fungal enzymes studied. ASNase from fungi showed high immunogenicity patterns. This knowledge is important in the search for new sources of asparaginases and demonstrates the usefulness of bioinformatics tools in the discovery of immunological features for the design of safer biopharmaceuticals.
Acknowledgements This work was supported by the National Commission for Scientific and Technological Research (CONICYT) Fellowship No. 21170061, DIUFRO Projects DI12-PEO1 and DIE14-0001 of the Universidad de La Frontera and by the Fundação de Amparo à Pesquisa do Estado de São Paulo (FAPESP No. 2013/08617-7).

\section{Compliance with ethical standards}

Conflict of interest The authors report no conflict of interest.

\section{References}

1. Ko RH, Jones TL, Radvinsky D et al (2015) Allergic reactions and antiasparaginase antibodies in children with high-risk acute lymphoblastic leukemia: a children's oncology group report. Cancer. https://doi.org/10.1002/cncr.29641

2. Tomizawa D, Kiyokawa N (2017) Acute lymphoblastic leukemia. In: Hematological disorders in children: pathogenesis and treatment. https://doi.org/10.1007/978-981-10-3886-0 
3. Katz AJ, Chia VM, Schoonen WM, Kelsh MA (2015) Acute lymphoblastic leukemia: an assessment of international incidence, survival, and disease burden. Cancer Causes Control. https://doi.org/10.1007/s10552-015-0657-6

4. Egler R, Ahuja S, Matloub Y (2016) L-asparaginase in the treatment of patients with acute lymphoblastic leukemia. J Pharmacol Pharmacother. https://doi.org/10.4103/0976500X.184769

5. Agrawal V, Hee Woo J, Borthakur G et al (2013) Red blood cellencapsulated L-asparaginase: potential therapy of patients with asparagine synthetase deficient acute myeloid leukemia. Protein Pept Lett. https://doi.org/10.2174/0929866138 05290426

6. Truelove E, Fielding AK, Hunt BJ (2013) The coagulopathy and thrombotic risk associated with L-asparaginase treatment in adults with acute lymphoblastic leukaemia. Leukemia. https ://doi.org/10.1038/leu.2012.290

7. Pieters R, Hunger SP, Boos J et al (2011) L-asparaginase treatment in acute lymphoblastic leukemia. Cancer. https://doi. org/10.1002/cncr.25489

8. Ettinger AR (1995) Pegaspargase (Oncaspar). J Pediatr Oncol Nurs. https://doi.org/10.1177/104345429501200110

9. Völler S, Pichlmeier U, Zens A, Hempel G (2018) Pharmacokinetics of recombinant asparaginase in children with acute lymphoblastic leukemia. Cancer Chemother Pharmacol. https ://doi.org/10.1007/s00280-017-3492-5

10. Avramis VI, Tiwari PN (2006) Asparaginase (native ASNase or pegylated ASNase) in the treatment of acute lymphoblastic leukemia. Int J Nanomed 1(3):241-254

11. Ramya LN, Doble M, Rekha VPB, Pulicherla KK (2012) L-asparaginase as potent anti-leukemic agent and its significance of having reduced glutaminase side activity for better treatment of acute lymphoblastic leukaemia. Appl Biochem Biotechnol. https://doi.org/10.1007/s12010-012-9755-z

12. Husain I, Sharma A, Kumar S, Malik F (2016) Purification and characterization of glutaminase free asparaginase from enterobacter cloacae: in-vitro evaluation of cytotoxic potential against human myeloid leukemia HL-60 cells. PLoS ONE. https ://doi.org/10.1371/journal.pone.0148877

13. Kafkewitz D, Bendich A (1983) Enzyme-induced asparagine and glutamine depletion and immune system function. Am J Clin Nutr 37(6):1025-1030

14. Haddy TB, Mosher RB, Nunez SB, Reaman GH (2006) Growth hormone deficiency after chemotherapy for acute lymphoblastic leukemia in children who have not received cranial radiation. Pediatr Blood Cancer. https://doi.org/10.1002/pbc.20485

15. Ranta S, Heyman MM, Jahnukainen K et al (2013) Antithrombin deficiency after prolonged asparaginase treatment in children with acute lymphoblastic leukemia. Blood Coagul Fibrinolysis. https://doi.org/10.1097/MBC.0b013e328363b147

16. Ohnuma T, Holland JF (1970) Biochemical and pharmacological studies with asparaginase in man. Cancer Res 30(9):2297-2305

17. Fu CH, Sakamoto KM (2007) PEG-asparaginase. Expert Opin Pharmacother. https://doi.org/10.1517/14656566.8.12.1977

18. Burke MJ (2014) How to manage asparaginase hypersensitivity in acute lymphoblastic leukemia. Futur Oncol. https://doi. org/10.2217/fon.14.138

19. Pui CH, Liu Y, Relling MV (2018) How to solve the problem of hypersensitivity to asparaginase? Pediatr Blood Cancer. https ://doi.org/10.1002/pbc.26884

20. Lopes AM, de Oliveira-Nascimento L, Ribeiro A et al (2017) Therapeutic L-asparaginase: upstream, downstream and beyond. Crit Rev Biotechnol. https://doi.org/10.3109/07388 551.2015.1120705
21. Panosyan EH, Seibel NL, Martin-Aragon S et al (2004) Asparaginase antibody and asparaginase activity in children with higher-risk acute lymphoblastic leukemia: Children's Cancer Group Study CCG-1961. J Pediatr Hematol Oncol. https://doi. org/10.1097/00043426-200404000-00002

22. Zalewska-Szewczyk B, Andrzejewski W, Młynarski W et al (2007) The anti-asparagines antibodies correlate with L-asparagines activity and may affect clinical outcome of childhood acute lymphoblastic leukemia. Leuk Lymphoma. https://doi.org/10.1080/10428190701292049

23. Ali U, Naveed M, Ullah A et al (2016) L-asparaginase as a critical component to combat Acute Lymphoblastic Leukaemia (ALL): a novel approach to target ALL. Eur J Pharmacol. https ://doi.org/10.1016/j.ejphar.2015.12.023

24. Fabry U, Körholz D, Jürgens $\mathrm{H}$ et al (1985) Anaphylaxis to L-asparaginase during treatment for acute lymphoblastic leukemia in children-evidence of a complement-mediated mechanism. Pediatr Res. https://doi.org/10.1203/00006450198519040-00017

25. Korholz D, Wahn U, Jurgens H, Wahn V (1990) Allergic reactions in treatment with L-asparaginase. Significance of specific $\lg \mathrm{E}$ antibodies. Monatsschr Kinderheilkd 138(1):23-25

26. Walenciak J, Wyka K, Janczar S et al (2018) Dynamic changes in specific anti-L-asparaginase antibodies generation during acute lymphoblastic leukemia treatment. Pharmacol Rep. https ://doi.org/10.1016/j.pharep.2018.11.002

27. Galindo-Rodríguez G, Jaime-Pérez JC, Salinas-Carmona MC et al (2017) Do immunoglobulin $G$ and immunoglobulin $E$ anti-L-asparaginase antibodies have distinct implications in children with acute lymphoblastic leukemia? A cross-sectional study. Rev Bras Hematol Hemoter. https://doi.org/10.1016/j. bjhh.2016.11.006

28. Korholz D, Urbanek R, Nurnberger $W$ et al (1987) Formation of specific IgG antibodies in L-asparaginase treatment. Distribution of IgG subclasses. Monatsschr Kinderheilkd 135(6):325-328

29. Avramis VI, Panosyan EH (2005) Pharmacokinetic/pharmacodynamic relationships of asparaginase formulations: The past, the present and recommendations for the future. Pharmacokinet, Clin. https://doi.org/10.2165/00003088-200544040-00003

30. Van Den Berg H (2011) Asparaginase revisited. Leuk Lymphoma. https://doi.org/10.3109/10428194.2010.537796

31. Asselin B, Rizzari C (2015) Asparaginase pharmacokinetics and implications of therapeutic drug monitoring. Leuk Lymphoma. https://doi.org/10.3109/10428194.2014.1003056

32. Zalewska-Szewczyk B, Andrzejewski W, Bodalski J (2004) Development of anti-asparaginase antibodies in childhood acute lymphoblastic leukemia. Pediatr Blood Cancer. https://doi. org/10.1002/pbc.20064

33. Arif HM, Hussain Z (2014) Important Sources and Medicinal Applications of L-asparaginase. Int J Pharma Res Rev IJPRR. 3(6):35-45

34. Cachumba JJM, Antunes FAF, Peres GFD et al (2016) Current applications and different approaches for microbial L-asparaginase production. Braz J Microbiol. https://doi.org/10.1016/j. bjm.2016.10.004

35. Prihanto AA, Wakayama M (2016) Marine Microorganism: an underexplored source of L-asparaginase. In: Advances in food and nutrition research. https://doi.org/10.1016/ bs.afnr.2016.07.005

36. Shrivastava A, Khan AA, Shrivastav A et al (2012) Kinetic studies of L-asparaginase from Penicillium digitatum. Prep Biochem Biotechnol. https://doi.org/10.1080/10826068.2012.672943

37. Farag AM, Hassan SW, Beltagy EA, El-Shenawy MA (2015) Optimization of production of anti-tumor L-asparaginase by free 
and immobilized marine Aspergillus terreus. Egypt J Aquat Res. https://doi.org/10.1016/j.ejar.2015.10.002

38. Mishra A (2006) Production of L-asparaginase, an anticancer agent, from Aspergillus niger using agricultural waste in solid state fermentation. Appl Biochem Biotechnol. https://doi. org/10.1385/ABAB:135:1:33

39. Nair A, Kumar R, Agalya Devi R, Balakrishnan K (2013) Screening of commonly available solid process residues as substrate for L-asparaginase production by aspergillus terreus MTCC 1782. Res J Pharm Biol Chem Sci. 4(2):1731-1737

40. Tippani Radhika (2012) Nutritional factors effecting the production of L-asparaginase by the Fusarium sp. Afr J Biotechnol. https://doi.org/10.5897/ajb10.2355

41. Zia MA, Bashir R, Ahmed I, Iftikhar T (2013) Production of L-asparaginase from aspergillus niger using agro wastes byproducts in submerged fermentation process. J Teknol (Sci Eng). https://doi.org/10.11113/jt.v62.1879

42. Santhosh Kumar D, Sobha K (2012) L-asparaginase from microbes: a comprehensive review. Adv Biores 3(4):137-157

43. Izadpanah F, Homaei A, Fernandes P, Javadpour S (2018) Marine microbial L-asparaginase: biochemistry, molecular approaches and applications in tumor therapy and in food industry. Microbiol Res. https://doi.org/10.1016/j.micres.2018.01.011

44. Krishnapura PR, Belur PD, Subramanya S (2016) A critical review on properties and applications of microbial L-asparaginases. Crit Rev Microbiol. https://doi.org/10.3109/10408 41X.2015.1022505

45. Loureiro CB, Borges KS, Andrade AF et al (2012) Purification and biochemical characterization of native and pegylated Form of L-asparaginase from aspergillus terreus and evaluation of its antiproliferative activity. Adv Microbiol. https://doi. org/10.4236/aim.2012.22019

46. Sundar SK, Sudarkodi C (2018) Anticancer activity of L-asparaginase from aspergillus oryzae against HEP G2 and hela cell lines. Int J Recent Sci Res. https://doi.org/10.24327/ijrsr .2018.0903.1838

47. Huang L, Liu Y, Sun Y et al (2014) Biochemical characterization of a novel L-asparaginase with low glutaminase activity from Rhizomucor miehei and its application in food safety and leukemia treatment. Appl Environ Microbiol. https://doi. org/10.1128/AEM.03523-13

48. Doriya K, Kumar DS (2016) Isolation and screening of L-asparaginase free of glutaminase and urease from fungal sp. 3 Biotech. https://doi.org/10.1007/s13205-016-0544-1

49. Benchamin D, Sreejai R, Sujitha S et al (2019) Anti-proliferative activity of L-asparaginase enzyme from fungi on breast cancer. J Pharmacogn Phytochem 8:407-410

50. Dias FFG, Ruiz ALTG, Della Torre A, Sato HH (2016) Purification, characterization and antiproliferative activity of L-asparaginase from Aspergillus oryzae CCT 3940 with no glutaminase activity. Asian Pac J Trop Biomed. https://doi.org/10.1016/j.apjtb .2016.07.007

51. Hassan SWM, Farag AM, Beltagy EA (2019) Purification, characterization and anticancer activity of L-asparaginase produced by marine aspergillus terreus. J Pure Appl Microbiol 12:18451854. https://doi.org/10.22207/jpam.12.4.19

52. Johnson G, Wu TT (2001) Kabat database and its applications: future directions. Nucl Acids Res. https://doi.org/10.1093/ nar/29.1.205

53. Bhasin M, Singh H, Raghava GPS (2003) MHCBN: a comprehensive database of $\mathrm{MHC}$ binding and non-binding peptides. Bioinformatics. https://doi.org/10.1093/bioinformatics/btg055

54. Saha S, Bhasin M, Raghava GPS (2005) Bcipep: a database of B-cell epitopes. BMC Genom. https://doi. org/10.1186/1471-2164-6-79
55. Gendel SM, Jenkins JA (2006) Allergen sequence databases. In: Molecular nutrition and food research. https://doi.org/10.1002/ mnfr.200500271

56. De Groot AS, McMurry J, Moise L (2008) Prediction of immunogenicity: in silico paradigms, ex vivo and in vivo correlates. Curr Opin Pharmacol. https://doi.org/10.1016/j.coph.2008.08.002

57. Jensen KK, Andreatta M, Marcatili P et al (2018) Improved methods for predicting peptide binding affinity to MHC class II molecules. Immunology. https://doi.org/10.1111/imm.12889

58. Ramya LN, Pulicherla KK (2015) Studies on deimmunization of antileukaemic L-asparaginase to have reduced clinical immunogenicity: an in silico approach. Pathol Oncol Res. https://doi. org/10.1007/s12253-015-9912-0

59. Rigouin C, Nguyen HA, Schalk AM, Lavie A (2017) Discovery of human-like L-asparaginases with potential clinical use by directed evolution. Sci Rep. https://doi.org/10.1038/s4159 8-017-10758-4

60. Mazor R, Eberle JA, Hu X et al (2014) Recombinant immunotoxin for cancer treatment with low immunogenicity by identification and silencing of human T-cell epitopes. Proc Natl Acad Sci. https://doi.org/10.1073/pnas.1405153111

61. Shaddel M, Ebrahimi M, Tabandeh MR (2018) Bioinformatics analysis of single and multi-hybrid epitopes of GRA-1, GRA-4, GRA- 6 and GRA-7 proteins to improve DNA vaccine design against Toxoplasma gondii. J Parasit Dis. https://doi. org/10.1007/s12639-018-0996-9

62. Gonçalves AB, Maia ACF, Rueda JA, Vanzela APDFC (2017) Fungal production of the anti-leukemic enzyme L-asparaginase: from screening to medium development. Acta Sci Biol Sci. https://doi.org/10.4025/actascibiolsci.v38i4.32993

63. Vimal A, Kumar A (2017) In vitro screening and in silico validation revealed key microbes for higher production of significant therapeutic enzyme L-asparaginase. Enzyme Microb Technol. https://doi.org/10.1016/j.enzmictec.2016.12.001

64. Gurunathan B, Sahadevan R (2012) Optimization of culture conditions and bench-scale production of L-asparaginase by submerged fermentation of Aspergillus terreus MTCC 1782. J Microbiol Biotechnol. https://doi.org/10.4014/jmb.1112.12002

65. Alhussaini MS (2013) Mycobiota of wheat flour and detection of a-Amylase and L-asparaginase enzymes. Life Sci J. 10(1):1112-1122

66. Sarquis MIDM, Oliveira EMM, Santos AS, da Costa GL (2004) Production of L-asparaginase by filamentous fungi. Mem Inst Oswaldo Cruz. https://doi.org/10.1590/S0074-0276200400 0500005

67. Yadav N, Sarkar S (2014) Production of L-asparaginase by fusarium oxysporum using submerged fermentation. Int J Pharm Sci Invent 3(6):32-40

68. Elzainy TA, Ali TH (2006) Detection of the antitumor glutaminase-asparaginase in the filamentous fungi. J Appl Sci. https:// doi.org/10.3923/jas.2006.1389.1395

69. Archana J, Raja P (2014) Production, purification and characterization of $\mathrm{L}$-asparaginase from Aspergillus nidulans by solid state fermentation. Eur J Biotechnol Bio 2:51-58

70. Nageswara S, Kamalakumari PV, Guntuku GS, Tadimalla P (2014) Production of L-asparaginase by solid state fermentation using marine fungus. BMR Biochem. https://doi.org/10.1007/s0025 9-010-1610-2

71. Gonzalez-Galarza FF, Christmas S, Middleton D, Jones AR (2011) Allele frequency net: a database and online repository for immune gene frequencies in worldwide populations. Nucl Acids Res. https://doi.org/10.1093/nar/gkq1128

72. Southwood S, Sidney J, Kondo A et al (1998) Several common HLA-DR types share largely overlapping peptide binding repertoires. J Immunol. https://doi.org/10.4049/jimmu nol.175.6.3603 
73. Dimitrov I, Bangov I, Flower DR, Doytchinova I (2014) AllerTOP: a server for in silico prediction of allergens. J Mol Model. https ://doi.org/10.1007/s00894-014-2278-5

74. Kelley LA, Mezulis S, Yates CM et al (2015) The Phyre2 web portal for protein modeling, prediction and analysis. Nat Protoc. https://doi.org/10.1038/nprot.2015.053

75. Heo L, Park H, Seok C (2013) GalaxyRefine: protein structure refinement driven by side-chain repacking. Nucl Acids Res. https://doi.org/10.1093/nar/gkt458

76. Davis IW, Leaver-Fay A, Chen VB et al (2007) MolProbity: allatom contacts and structure validation for proteins and nucleic acids. Nucl Acids Res. https://doi.org/10.1093/nar/gkm216

77. Ponomarenko J, Bui HH, Li W et al (2008) ElliPro: a new structure-based tool for the prediction of antibody epitopes. BMC Bioinform. https://doi.org/10.1186/1471-2105-9-514

78. Kirsch JR, Verma D, Griswold KE et al (2017) Computationally optimized deimmunization libraries yield highly mutated enzymes with low immunogenicity and enhanced activity. Proc Natl Acad Sci. https://doi.org/10.1073/pnas.1621233114

79. Asgari S, Ebrahim-Habibi A, Mahdavi M et al (2017) Therapeutic protein deimmunization by T-cell epitope removal: antigenspecific immune responses in vitro and in vivo. APMIS. https:// doi.org/10.1111/apm.12682

80. Parker AS, Griswold KE, Bailey-Kellogg C (2012) Structureguided deimmunization of therapeutic proteins. In: Lecture notes in computer science (including subseries Lecture notes in artificial intelligence and lecture notes in bioinformatics). https://doi.org/10.1089/cmb.2012.0251

81. Cantor JR, Yoo TH, Dixit A et al (2011) Therapeutic enzyme deimmunization by combinatorial T-cell epitope removal using neutral drift. Proc Natl Acad Sci USA. https://doi.org/10.1073/ pnas. 1014739108

82. Mahboobi M, Sedighian H, Hedayati CHM et al (2017) Applying bioinformatic tools for modeling and modifying type II E. coli L-asparginase to present a better therapeutic agent/drug for acute lymphoblastic leukemia. Int J Cancer Manag. https://doi. org/10.5812/ijcm.5785

83. Savitri Asthana N, Azmi W (2003) Microbial L-asparaginase: a potent antitumour enzyme. Indian J Biotechnol 2(2):184-194

84. Jha S, Pasrija D, Sinha R, Singh H (2012) Microbial L-asparaginase: a review on current scenario and future prospects. Int J Pharma Sci 3(9):3076-3090

85. Singh HR, Jha SK (2013) MICROBIAL L-asparaGINASE: present and future prospective. Int J Innov Res Sci Eng Technol 2(11):7031-7051

86. Bachmann MF, Rohrer UH, Kündig TM et al (1993) The influence of antigen organization on B cell responsiveness. Science. https ://doi.org/10.1126/science.8248784

87. Liu W, Chen YH (2005) High epitope density in a single protein molecule significantly enhances antigenicity as well as immunogenecity: a novel strategy for modern vaccine development and a preliminary investigation about $\mathrm{B}$ cell discrimination of monomeric proteins. Eur J Immunol. https://doi.org/10.1002/ eji.200425749

88. Liu W, Peng Z, Liu Z et al (2004) High epitope density in a single recombinant protein molecule of the extracellular domain of influenza A virus M2 protein significantly enhances protective immunity. Vaccine. https://doi.org/10.1016/j.vacci ne.2004.05.028

89. Lissabet JFB (2018) A large-scale immunoinformatics analysis of the human papillomaviruses reveals a common $\mathrm{E} 5$ oncoprotein-pattern to evade the immune response. Gene Rep. https ://doi.org/10.1016/j.genrep.2017.10.008

90. De Groot AS, Moise L, Liu R et al (2014) Immune camouflage: Relevance to vaccines and human immunology. Vaccines Immunother, Hum. https://doi.org/10.4161/hv.36134
91. He L, De Groot AS, Gutierrez AH et al (2014) Integrated assessment of predicted MHC binding and cross-conservation with self reveals patterns of viral camouflage. BMC Bioinform. https ://doi.org/10.1186/1471-2105-15-S4-S1

92. Wetzler M (2014) Asparaginase allergies: it's all in the genes. Blood. https://doi.org/10.1182/blood-2014-07-585919

93. Fernandez CA, Smith C, Yang W et al (2014) HLA-DRB ${ }^{*} 07: 01$ is associated with a higher risk of asparaginase allergies. Blood. https://doi.org/10.1182/blood-2014-03-563742

94. Jemmy Christy H, Alex Anand D (2014) Insilico study of HLADRB 1*0101 allele association in Nevirapine (NVP) induced hypersensitivity among Indian HIV-infected population. Int J PharmTech Res 6(7):1957-1962

95. Martin AM, Nolan D, James I et al (2005) Predisposition to nevirapine hypersensitivity associated with HLA-DRB $1 * 0101$ and abrogated by low CD4 T-cell counts. AIDS. https://doi. org/10.1097/00002030-200501030-00014

96. Vitezica ZG, Milpied B, Lonjou C et al (2008) HLA-DRB $1 * 01$ associated with cutaneous hypersensitivity induced by nevirapine and efavirenz. AIDS. https://doi.org/10.1097/QAD.0b013e3282f37812

97. Negrini S, Becquemont L (2017) HLA-associated drug hypersensitivity and the prediction of adverse drug reactions. Pharmacogenomics 18:1441-1457. https://doi.org/10.2217/ pgs-2017-0090

98. Hoffmann S, Cepok S, Grummel V et al (2008) HLA-DRB1*0401 and HLA-DRB $1 * 0408$ Are Strongly Associated with the Development of Antibodies against Interferon- $\beta$ Therapy in Multiple Sclerosis. Am J Hum Genet. https://doi.org/10.1016/j. ajhg.2008.07.006

99. Kutszegi N, Yang X, Gézsi A et al (2017) HLA-DRB1*07:01-HLADQA 1*02:01-HLADQB1* 02:02 haplotype is associated with a high risk of asparaginase hypersensitivity in acute lymphoblastic leukemia. Haematologica. https://doi.org/10.3324/haema tol.2017.168211

100. Müller HJ, Beier R, Löning L et al (2001) Pharmacokinetics of native Escherichia coli asparaginase (Asparaginase medac) and hypersensitivity reactions in ALL-BFM 95 reinduction treatment. Br J Haematol. https://doi.org/10.104 6/j.1365-2141.2001.03009.x

101. August KJ, Miller WP, Dalton A, Shinnick S (2013) Comparison of hypersensitivity reactions to PEG-asparaginase in children after intravenous and intramuscular administration. J Pediatr Hematol Oncol. https://doi.org/10.1097/MPH.0b013e31828e5471

102. dos Santos AC, Land MGP, da Silva NP et al (2017) Reactions related to asparaginase infusion in a 10-year retrospective cohort. Rev Bras Hematol Hemoter. https://doi.org/10.1016/j. bjhh.2017.08.002

103. Hijiya N, Van Der Sluis IM (2016) Asparaginase-associated toxicity in children with acute lymphoblastic leukemia. Leuk Lymphoma. https://doi.org/10.3109/10428194.2015.1101098

104. Potocnakova L, Bhide M, Pulzova LB (2016) An introduction to B-cell epitope mapping and in silico epitope prediction. J Immunol Res. https://doi.org/10.1155/2016/6760830

105. Sahay B, Nguyen CQ, Yamamoto JK (2017) Conserved HIV epitopes for an effective HIV vaccine. J Clin Cell Immunol. https ://doi.org/10.4172/2155-9899.1000518

106. Rezende CMF, Coitinho JB, Costa M et al (2018) Biochemical analysis and identification of linear B-cell epitopes from recombinant Sm21.7 antigen from Schistosoma mansoni. Mol Immunol. https://doi.org/10.1016/j.molimm.2018.05.019

Publisher's Note Springer Nature remains neutral with regard to jurisdictional claims in published maps and institutional affiliations. 